theory of an HIV-PrP relationship. Furthermore, available sequence data allow the possibility of unequal rates to be excluded by relative rate tests? ${ }^{7}$. For these reasons, the burden of proof of an HIV-PrP relationship still lies with Haseltine and colleagues.

Michael J. Braun

University of Cincinnati,

Cincinnati, Ohio 45221, USA

Matthew A. Gonda

Frederick Cancer Research Facility,

Frederick, Maryland 21701, USA

National Biomedical Research

David G. George

Foundation,

Georgetown University Medical Center, Washington, DC 20007, USA

J. FERnANDo BAZAN

Department of Biophysics,

University of California,

Berkeley, California 94720, USA

Robert J. FletTERICK

Departments of Biochemistry,

Biophysics and Neurology,

University of California,

San Francisco, California 94143, USA

1. Braun, M.J. \& Gonda, M.A. Nature 325, 113-114 (1987)

2. Bazan, J.F., Fletterick, R.J. \& Prusiner, S.B. Nature 325, 581 (1987).

3. Haseltine, W. A. \& Patarca, R. Nature 323, 115-116 (1986).

4. Patarca, R.et al. Nature 326, 749 (1987).

5. Gonda, M.A. et al. Proc. natn. Acad. Sci. U.S.A. 83, $4007-$ 4011 (1986).

6. Guyader, M. et al. Nature 326, 662-669 (1987).

7. Sarich, V.M. \& Wilson, A.C. Proc. natn. Acad. Sci. U.S.A. 58, 142-148 (1967)

\section{Biological regulation of climate}

SIR-The requirement for a biological regulation of the climate, according to Charlson et al. ${ }^{1}$, is first, that the source of most of the cloud-condensation nuclei (CCN) over the remote oceans is dimethylsulphide, and second, that the salt particles always found in the marine atmosphere make a negligible contribution to the CCN. They state that sea-salt particle concentrations ". . . at cloud height are typically not more than $1 \mathrm{~cm}^{-3}$..." We believe that the particle concentrations are at least an order of magnitude more.

The classic sea-salt particle-size distributions obtained by Woodcock ${ }^{2}$ at cloud base altitudes as a function of wind speed do indeed show concentrations of only about $1 \mathrm{~cm}^{-3}$, but his sampling method did not allow him to collect particles smaller than $2-\mu \mathrm{m}$ radius as a droplet of seawater. However, it was clear from the slope of his cumulative curves that smaller salt particles existed. Later, with refinements to his sampling method ${ }^{3}$, he extended his size distributions down to nearly $0.2-\mu \mathrm{m}$ radius and found salt particle concentrations of about $15 \mathrm{~cm}^{-3}$. His earlier wind-speed dependent cumulative curves $^{2}$, if extrapolated, converge at a concentration of about $15 \mathrm{~cm}^{-3}$. This suggests that salt-particle concentrations of around $15 \mathrm{~cm}^{-3}$, due to the long residence time of the small salt particles, will change little with changing wind speed.

There is further evidence for sea-salt particles contributing significantly to the CCN. From measurements along the shore in Hawaii, Blanchard ${ }^{4}$ deduced that the salt particle flux to the atmosphere in a breaking wave is about $4,000 \mathrm{~cm}^{-2} \mathrm{~s}^{-1}$. Recently, in laboratory experiments to model a breaking wave at sea, Cipriano et al. ${ }^{5}$ obtained nearly the same value, $3,500 \mathrm{~cm}^{-2} \mathrm{~s}^{-1}$. Assuming that only 0.2 of these were large enough to be activated as $\mathrm{CCN}$ at 0.5 per cent supersaturation in clouds, and making other reasonable assumptions for the per cent whitecap coverage at sea and particle residence time, Cipriano et al. ${ }^{5}$ calculated that the measured flux was sufficient to produce concentrations of sea-salt CCN of $18 \mathrm{~cm}^{-3}$ in the lowest kilometre of the atmosphere.

Finally, measurements made from aircraft by Dinger et al. ${ }^{6}$ in the trade winds near Puerto Rico of the volatility of the $\mathrm{CCN}$ showed that above the temperature inversion all $\mathrm{CCN}$ are volatile, but below the inversion the fraction of $\mathrm{CCN}$ that is non-volatile increased as they approached the sea. Concentrations of at least $20 \mathrm{~cm}^{-3}$ were found at cloud base altitudes, and they assumed this to be sea salt.

It may be true that the source of most of the $\mathrm{CCN}$ is dimethylsulphide, but with a steady-state background concentration of sea-salt particles of $15-20 \mathrm{~cm}^{-3}$, all of which can serve as $\mathrm{CCN}$, a biological regulation of the climate is less obvious.

Duncan C. Blanchard

RAMON J. CiPRIANO

Atmospheric Sciences Research Center,

State University of New York at Albany,

Albany, New York 12222, USA

1. Charlson, R.J., Lovelock, J E., Andreae M.O.\& Warren, S. G. Nature 326, 655-661 (1987)

Woodcock, A.H.J. Meteor. 10, 362-371 (1953).

3. Woodcock, A.H.J. geophys. Res. 77, 5316-5321 (1972)

4. Blanchard, D.C. J. rech. Atmos. 4, 1-6 (1969).

5. Cipriano, R.J., Monahan, E.C., Bowyer, P.A. \& Woolf, D.K. J. geophys. Res. 92, 6569-6576 (1987).

6. Dinger, J.E., Howell, H.B. \& Wojciechowski, T.A. J. atmos. Sci. 27, $791-797$ (1970)

Charlson and Warren Reply - We wish to make four points. First, regulation of climate by $\mathrm{CCN}$ from biologically generated dimethylsulphide does not require "that the salt particles always found in the marine atmosphere make a negligible contribution to the $\mathrm{CCN}$ ", as stated by Blanchard and Cipriano. Our hypothesis requires only that the biologically produced CCN from dimethylsulphide alters the particle number concentration sufficiently to produce climatologically important shifts in albedo. Changes of only 30 per cent in the CCN numbers appear to be important to climate.

Second, we do not wish to enter into a debate as to whether the sea-salt $\mathrm{CCN}$ concentrations in clouds are 1 or $10 \mathrm{~cm}^{-3}$.
What is more important is what fraction of the measured total droplet concentration of $30-200 \mathrm{~cm}^{-3}$ is nucleated on sea-salt and what fraction is nucleated on dimethylsulphide-derived sulphate. Even if seasalt $\mathrm{CCN}$ concentration was $20 \mathrm{~cm}^{-3}$ (which we believe is too high) it appears that sulphate $\mathrm{CCN}$ is still present in sufficient abundance to control the overall droplet concentration and hence the albedo.

Third, we chose to reference the excellent review of data on $\mathrm{CCN}$, sea-salt and sulphate number concentrations by Pruppacher rather than to lengthen an already long paper. We certainly would have included the pioneering work of Woodcock, Blanchard and others had we had the space. We too believe the preponderance of opinion is that the fraction of droplets nucleated by sea-salt is small.

Finally, we believe that Blanchard and Cipriano would concur that more data on actual CCN composition and concentrations would help to refine the quantitative aspects of this intriguing hypothesis.

Robert J. CHARLSON STEPHEN G. WARREN Department of Atmospheric Physics,

University of Washington,

Seattle, Washington 98195, USA

\section{Contributions to a quest}

SIR-My principal concern with the News and Views article entitled "The end of the quest" by Paul M. Vanhoutte (Nature 327, $459-460 ; 1987)$ is his omission of reference to the pertinent research conducted in this laboratory which provides strong experimental evidence that endotheliumderived relaxing factor (EDRF) is nitric oxide (NO). Instead, only Robert F. Furchgott is referenced as having proposed that EDRF may be NO. The reference quoted was a monograph to be published in Mechanisms of Vasodilation (ed. Vanhoutte, P.M.; Raven, New York), which represents a talk that was delivered at a symposium held in Rochester in July 1986. What is disconcerting about Vanhoutte's omission of our own contribution is that we also have a monograph to be published in the same book. This represents a talk that I delivered at the same symposium. Our monograph specifically addresses the close similarities in the biological properties of EDRF and NO, and contains our hypothesis that EDRF is NO or a closely related nitroso species. As Vanhoutte organized the symposium and edited both monographs, it is particularly distressing to us that fair and proper recognition was not given to our major contributions in this exciting area of research.

Department of Pharmacology,

UCLA School of Medicine,

Center for the Health Sciences,

Los Angeles, California 90024, USA 